\title{
The Dissertation Symposia IN Chemical OcEANography (DISCO)
}

\author{
By Neil R. Andersen
}

\section{S} Oceanography Program of the National Science Foundation and the Oceanic Chemistry Program of the Office of Naval Research have been jointly convening a series of Dissertation Symposia in Chemical Oceanography (DISCO). In recent years the Sea Grant Program of the National Oceanic and Atmospheric Administration has also co-sponsored the meetings. On several occasions, The United Nations Educational, Scientific and Cultural Organization has provided travel grants to individuals from developing countries. The $\mathrm{Na}$ tional Environmental Research Council of the U.K. and the Norwegian Research Council also have sponsored several participants.

The symposia are dedicated to soon-tobe or recent Ph.D. graduates in chemical oceanography. From an agency perspective, we are interested in becoming more familiar with the ideas being formulated by these individuals as they enter the field of oceanography and pursue their research interests. It is important that these new graduates have the best information available on the research climate and opportunities in their areas of interest. It is also important for them to possess an insight into the structure. missions and modes of operation of the co-sponsoring agencies. as well as the procedures to follow in seeking research support from these agencies. The DISCO symposia thus bring together, in scientific discussion and interaction, young scientists about to enter the field of chemical oceanography as new graduates. Future professional relationships are forged at these meetings, and the entire oceanographic community benefits by becoming more aware of the innovations and efforts of young workers.

Neil R. Andersen, Chemical Occanography Program. National Science Foundation. Washington. DC 20550
Because the symposia were created for the newest Ph.D.'s, certain general guidelines were formulated and have been followed since the first meeting. First, major professors of the participants and their department heads and deans are not invited to attend the meeting. The reason for this is to avoid the risk of creating barriers to open and frank discussions of papers being presented. Second, participation is limited to insure that each participant has ample time to present his or her thesis research, and that sufficient time is available for in-depth discussion and debate. Third, selection for the meeting is made on the basis of an extended abstract. The abstracts are printed in final form approximately one month after the close of the symposium, providing an opportunity for the authors to make revisions as a consequence of the discussions that took place during the meeting. The abstracts are available in bound form from the co-sponsoring agencies. Finally, time is made available to the participants not only to initiate and hold informal sessions, but also to address certain topics raised by the agencies at the opening session. The results of these informal sessions are presented by spokespersons of the groups formed to address the assignments.

The symposia have been convened at approximately 18 -month intervals. Therefore an applicant must have received his or her degree within the nine months preceding the symposium. or alternatively the department chairman or dean must certify that the applicant probably will be granted a degree within nine months after the completion of the symposium. By following this schedule we assure that all graduates will have an opportunity to be considered for participation.

As of October 1988, 190 new and soonto-become Ph.D.'s have participated in seven DISCO symposia over the past decade. During this period we have benefitted from having 17 foreign participants representing 10 countries outside the U.S. (Belgium, Canada, France, India, Japan, Norway, Pakistan. People's Republic of China, South Korea and the United Kingdom).

The eighth DISCO symposium was convened during 14-18 November 1988 at the East-West Center, University of Hawaii Campus, Honolulu, Hawaii. The main session topics were titled Physical Chemistry and Photochemistry, Organics and Nutrients, Tracers. Sediment Diagnosis. Trace Metals, and Federal Programs in Oceanography. The invited participants are listed in the appended table.

It is anticipated that DISCO-IX will be convened in February of 1990 . Individuals interested in being considered for that symposium should be alert to announcements that will appear by Spring 1989. or alternatively at that time they should contact the organizer. Mrs. Mary-Francis Thompson. American Institute of Biological Sciences, 73011 th St., NW, Washington. DC 20001-4584, for an application.

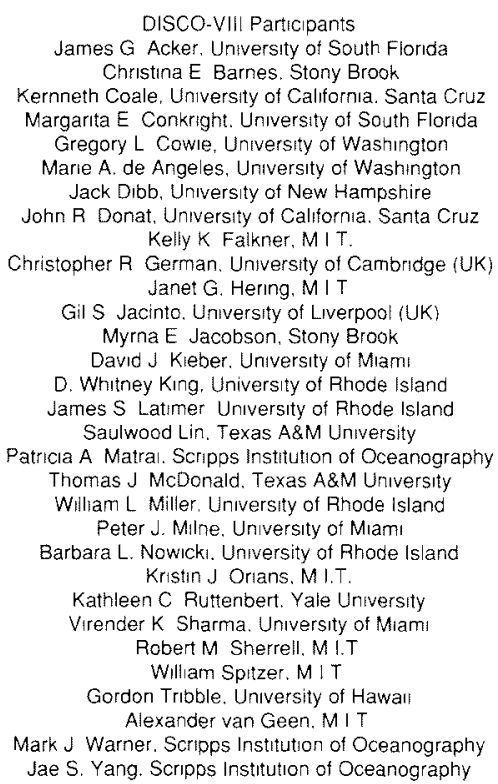

